\title{
Smoking Habits and Tar Levels in a New American Cancer Society Prospective Study of 1.2 Million Men and Women ${ }^{1}$
}

\author{
Steven D. Stellman, Ph.D., ${ }^{2}$ and Lawrence Garfinkel, M.A. ${ }^{2,3}$
}

\begin{abstract}
In 1982 the American Cancer Society (ACS) enrolled over 1.2 million American men and women in a prospective mortality study of cancer and other causes in relation to environmental and life-style factors. Biennial follow-up is planned through 1988. At the time of enrollment, $23.6 \%$ of the men and $20.0 \%$ of the women were current smokers of cigarettes. Compared with a similar ACS study of 1 million subjects enrolled 23 years earlier, among men the proportion of current smokers was halved and that of ex-smokers doubled, while among women the proportion of ever-smokers increased by $10 \%$ and that of ex-smokers quadrupled. Most smokers of filter cigarettes had smoked nonfiltered cigarettes earlier in life. The median year for switching to filters was 1964, the year of the first Surgeon General's report. More than one-third of male smokers' and one-half of female smokers' current brands had tar yields below $12 \mathrm{mg}$; less than $9 \%$ of male smokers' and $4 \%$ of female smokers' current brands had tar yields of $20.2 \mathrm{mg}$ or more (nonfilters). The study population differed in many respects from the general U.S. population; the study population had, for example, a much higher average educational level. Nevertheless, distributions of smoking habits changed a few percentage points after adjustment to the educational level of the general population.-J J $1986 ; 76: 1057-1063$.
\end{abstract}

Striking changes in cigarette smoking patterns have been observed in the United States over the last 30 years. According to various surveys the percent of male cigarette smokers dropped significantly from about $55 \%$ in the early 1950's to about $30 \%$ in the 1980 's $(1,2)$. During the same period of time, there were only slight increases in the percent of women smokers $(\approx 30-35 \%)$; but, in recent years, there has been a decrease to below $30 \%$. In 1986 the ACS estimates that more than 37 million Americans have quit smoking cigarettes (3). In addition, the tar and nicotine contents of American cigarettes have decreased substantially. According to industry estimates, sales-weighted tar levels dropped from $38.4 \mathrm{mg}$ in 1956 to $14 \mathrm{mg}$ in 1980 . Nicotine levels dropped from $2.8 \mathrm{mg}$ in 1956 to 1.0 in 1980 (4).

Smokers of cigarettes with reduced tar and nicotine for at least 10 years have shown lower lung cancer death rates compared to those who smoked high-tar or nonfilter cigarettes $(5,6)$. But these studies were based on the type of cigarettes Americans were smoking in the 1960's and 1970's, and tar and nicotine deliveries have been reduced further since then. There have been no studies showing whether lung cancer mortality is further reduced in those who smoke cigarettes with less than 10 $\mathrm{mg}$ tar. Some investigators have shown, moreover, that smokers tend to compensate for the inhalation of less nicotine by smoking more cigarettes per day (7) or by inhaling more deeply $(8,9)$.
We report here the smoking habits of about 1.2 million men and women, over the age of 30 years, enrolled in a long-term prospective study in 1982. We present further evidence of the massive changes in cigarette smoking patterns that have taken place in the United States over the past 30 years.

\section{SUBJECTS AND METHODS}

In this study, CPS-2, more than 77,000 ACS volunteer "researchers" enrolled over 1.2 million men and women in a long-term prospective study. Those enrolled, who were usually friends, neighbors, or relatives of the volunteers, completed a four-page confidential questionnaire on history of cancer and other diseases; occupational exposures; use of medicines and vitamins; menstrual and reproductive history; diet and drinking habits; and numerous other habits, including smoking. Enrollment was by family groups with at least 1 person in the household 45 years of age or older. All members of the household over 30 years of age were asked to complete a questionnaire.

Enrollment of subjects was carried out in all 50 states, the District of Columbia, and Puerto Rico. It began in September 1982 and was essentially completed by the end of November 1982. Every 2d year, the researchers are sent a list of the persons enrolled and asked to check whether the enrollees are alive or dead. For death, the researchers record the date and place. Death certificates are subsequently obtained through state health departments. The first follow-up was in 1984; others are planned for 1986 and 1988 .

A total of 521,555 men and 685,748 women were initially enrolled. A small proportion of these were found to be ineligible (too young) or had contributed unusable questionnaires. This analysis is based upon responses from 508,656 men and 676,640 women.

ABbREviaTIONS USED: ACS = American Cancer Society; CPS- $1=$ Cancer Prevention Study 1; CPS-2 $=$ Cancer Prevention Study 2; FTC $=$ Federal Trade Commission.

\footnotetext{
1 Received August 19, 1985; accepted February 5, 1986.

${ }^{2}$ Department of Epidemiology and Statistics, American Cancer Society, Inc, 4 West 35 th St., New York, NY 10001.

${ }^{3}$ We gratefully acknowledge the indispensable assistance of Margaret Mushinski and Melody Davis in organizing and training researchers and managing the large quantities of data. We especially thank the 77,000 American Cancer Society volunteers for their role in data collection.
} 


\section{RESULTS}

\section{Demography of Sample}

The design and conduct of this study follow closely those of an earlier prospective study, CPS-1, carried out by the ACS between 1959 and 1972 (10). Because of the similarity in the characteristics of the subjects in the two studies, changes in population characteristics over time, especially smoking habits, are more appropriately made by comparing CPS-2 data with CPS-1, rather than with population samples.

The age distributions of both CPS-1 and CPS-2 are illustrated in text-figure 1 . The mean age of the CPS-2 population was 57.6 for men and 56.8 for women, which were substantially greater than in CPS-1. Table 1 shows the distribution of three important demographic factors: marital status, religion, and ethnicity. Seventy-five percent of the women and $94 \%$ of the men were currently married, while $1.6 \%$ of men and $14.6 \%$ of women were widowed. We identified over 400,000 married couples enrolled in family units. This will enable us to do some analyses using a husband-wife pair as a unit, rather than individuals, for studies of involuntary smoking, dietary concordance, etc. The distribution of religion was about $61 \%$ Protestant, $25 \%$ Catholic, and $4 \%$ Jewish, with over $2 \%$ belonging to the Mormon religion, owing to a very high enrollment in the State of Utah.

Minority groups were underrepresented in the sample compared to the general population: About $4 \%$ were black and less than $1 \%$, Hispanic.

Since education is a major correlate (and likely a determinant) of smoking habits, this aspect of our study group must constantly be kept in mind when smoking data are assessed. Table 2 gives the educational distribution. Over $36 \%$ of the men and $25 \%$ of the women were college graduates, which made this group substantially better educated than the public at large. At the opposite end of the social spectrum, only $7.4 \%$ of the men and $5.6 \%$ of the women in our study had an eighth grade education or below. These proportions were considerably smaller than comparable percentages for the general
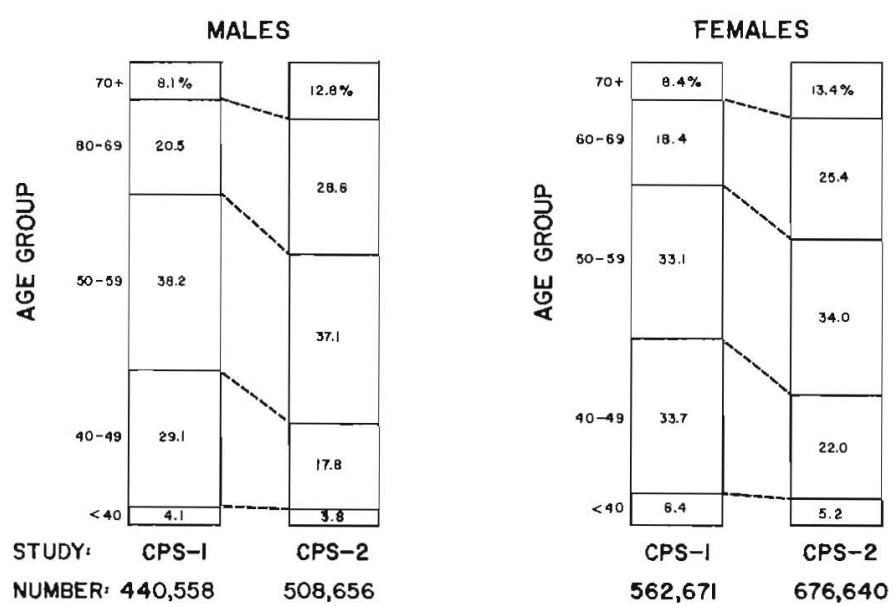

TEXT-FIGURE 1.-Changes in base-line age, yr, distribution of populations between CPS-1 (1959) and CPS-2 (1982).
TABLE 1.-Distribution of main demographic factors

\begin{tabular}{|c|c|c|c|c|c|c|}
\hline \multirow{2}{*}{ Sex } & \multicolumn{6}{|c|}{ Marital status } \\
\hline & Single & Separated & Widowed & $\mathrm{Ma}$ & ried & Divorced \\
\hline Male & 2.1 & 0.4 & 1.6 & & 1.2 & 1.7 \\
\hline \multirow[t]{3}{*}{ Female } & 4.2 & 0.8 & 14.6 & & 6.3 & 5.1 \\
\hline & \multicolumn{6}{|c|}{ Religion } \\
\hline & Protestant & it Catholic & Jewish & $\operatorname{LDS}^{a}$ & "None" & " Other \\
\hline Male & 61.6 & 24.1 & 4.8 & 2.7 & 3.2 & 3.6 \\
\hline \multirow[t]{3}{*}{ Female } & 61.0 & 25.3 & 4.3 & 2.5 & 1.5 & 4.1 \\
\hline & \multicolumn{6}{|c|}{ Ethnic group } \\
\hline & White & Black & Hispanic & & iental & Other \\
\hline Male & 94.5 & 3.7 & 0.8 & & 0.7 & 0.3 \\
\hline Female & 93.2 & 4.9 & 0.9 & & 0.7 & 0.3 \\
\hline
\end{tabular}

${ }^{a} \operatorname{LDS}=$ Church of Jesus Christ of the Latter-Day Saints (Mormons).

population. For instance, at age 55-64 years, the percentages of CPS-2 males and females having at most an eighth grade education were $6.2 \%$ and $4.9 \%$, respectively, whereas, at age 55-64 years, in the general white population in $1980-81$, they were $19.6 \%$ and $17.6 \%$ (11). Even so, inclusion of over 73,000 men and women with eighth grade schooling or below will make possible many useful comparisons based upon socioeconomic differences within the CPS-2 cohort.

\section{Smoking Habits}

Smoking habits are given for both men and women in table 3. We tried to accurately classify subjects, but a small number of questionnaires defied sensible categorization. For example, $1.9 \%$ of the women gave inconsistent data of being a current smoker as well as an exsmoker. Some subjects gave no smoking information at all; such persons are termed "unclassifiable" in table 3. Text-figure 2 shows the unadjusted distribution of smoking habits in men and women, compared with corresponding categories in CPS-1. Removal of unclassifiable subjects altered percentages slightly, compared with percentages in table 3 . Adjustment of the CPS-2 smoking distributions to the age distribution of the younger CPS- 1 population altered these percentages by at most $1.5 \%$ (see legend for text-fig. 2).

Drastic differences were apparent between the two cohorts. In 1982, the proportion of men who had never

TABLE 2.-Educational distribution of subjects

\begin{tabular}{lrr}
\hline \multicolumn{1}{c}{ Education } & Males, \% & Females, \% \\
\hline Eighth grade or less & 7.4 & 5.6 \\
Some high school & 8.7 & 8.4 \\
High-school graduate & 20.0 & 30.6 \\
Vocational school & 6.6 & 5.9 \\
Some college & 20.6 & 24.4 \\
College graduate & 17.8 & 14.7 \\
Graduate school & 18.8 & 10.4 \\
\hline
\end{tabular}


TABLE 3.-Distribution of smoking habits ${ }^{a}$

\begin{tabular}{ccc}
\hline Smoking habits & Males, \% & Females, \% \\
\hline Never smoked regularly & $(25.0)$ & $(52.5)$ \\
Ever smoked cigarettes & $(63.6)$ & $(42.4)$ \\
Current cigarette smoker & 23.6 & 20.0 \\
Only cigarettes & 20.8 & \\
With pipe and/or cigar & 2.8 & \\
Ex-cigarette smoker & 40.0 & 20.5 \\
Only cigarettes & 31.0 & \\
Ever pipe and/or cigar & 9.0 & \\
Can't tell & - & 1.9 \\
Pipe and/or cigar smoker & $(8.1)$ & \\
Current smoker & 4.4 & \\
Ex-smoker & 3.7 & \\
Unclassifiable & $(3.2)$ & $(5.0)$ \\
\hline
\end{tabular}

${ }^{a}$ Numbers in parentheses are subtotals that before rounding add up to a total of $100 \%$ for males and $100 \%$ for females. $-=$ not applicable.

smoked increased by about $3 \%$, while ex-smokers had more than doubled and current smokers had been halved. For females, the proportion of ever-smokers increased by over $10 \%$, with a large increase in exsmokers.

\section{Trends in Smoking Parameters}

Text-figures 3-5 show the values of critical smoking dosage parameters in different age and sex groups. In text-figure 3, for example, the age at which smokers born at different times reported they began to smoke is seen to drift gradually downward for more recent birth cohorts. Many years ago, the few women who smoked cigarettes at all tended to take up the habit later in life. In recent times, teens and preteens, particularly girls, are experimenting at much younger ages than ever before $(1,12)$.

Text-figure 4 shows the duration of smoking filter and nonfilter cigarettes. The filter and nonfilter curves

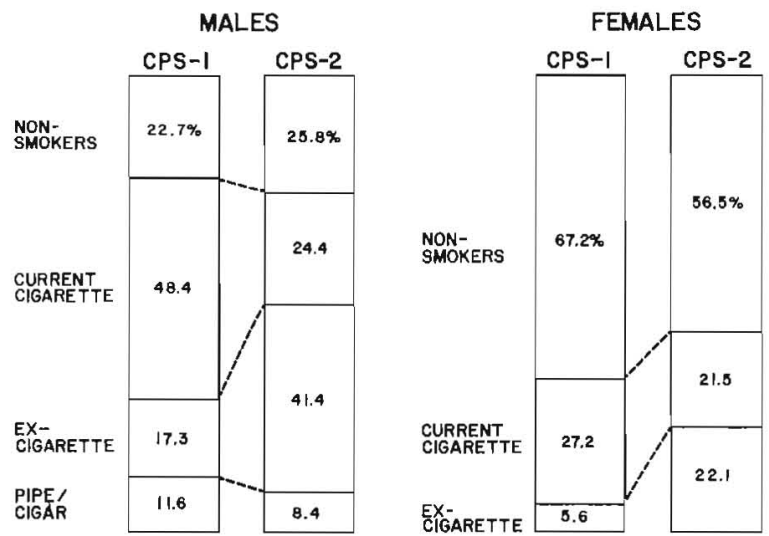

TEXT-FIGURE 2.-Changes in base-line distributions of smoking habits between CPS-1 (1959) and CPS-2 (1982). If adjusted to the age distribution of CPS-1, the distributions for CPS-2 males are: nonsmokers, 26.2\%; current cigarette smokers, $25.8 \%$; ex-cigarette smokers, $39.9 \%$; pipe and/or cigar smokers, $8.2 \%$. For CPS-2 females: nonsmokers, $55.0 \%$; current cigarette smokers, $22.6 \%$; ex-cigarette smokers, $22.4 \%$.

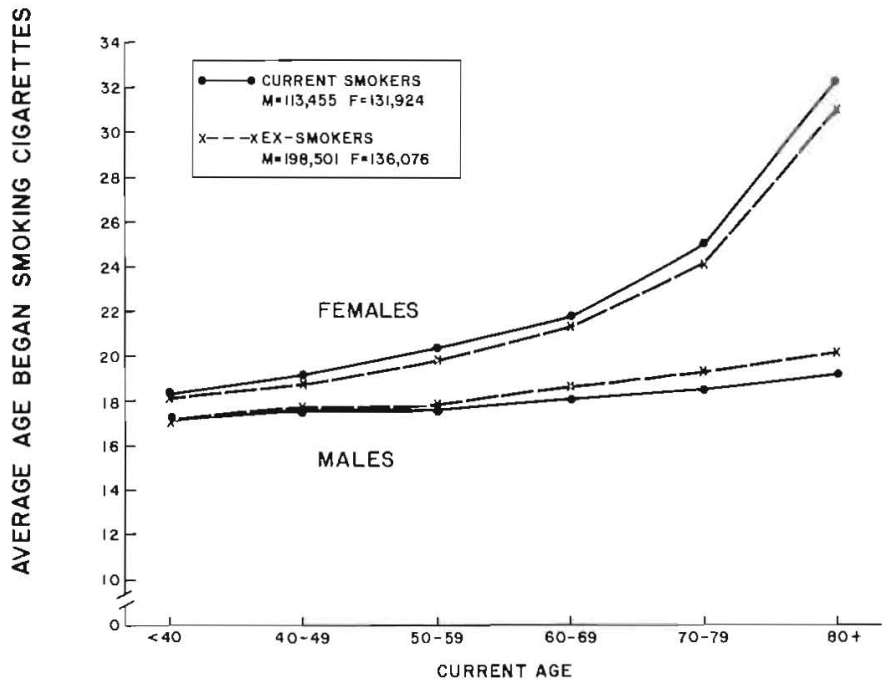

TEXT-FIGURE 3.-Average age (yr) at which subjects began to smoke cigarettes, by current smoking habit, current age, and sex (M, males; $F$, females).

did not necessarily add up to the total curve, since different subpopulations contributed to each curve, besides which some people may have smoked both types of cigarettes concurrently. While both the total and nonfilter curves rose linearly with age, as one would expect in a group where individuals in specific cohorts started to smoke at about the same time, the filter-smoking curves were nearly flat. The majority of current filter cigarette smokers had also smoked nonfilters at some earlier time in life. The average number of years of filter smoking for this group was 18 years prior to enrollment, or about the time of the landmark Surgeon General's report (13), which was a culmination of a new public awareness of hazards of cigarette smoking. The older groups of current filter cigarette smokers ( $\geq 60$ yr of age) also exhibited a secondary small peak of switching from nonfilters about 10 years prior to enrollment.

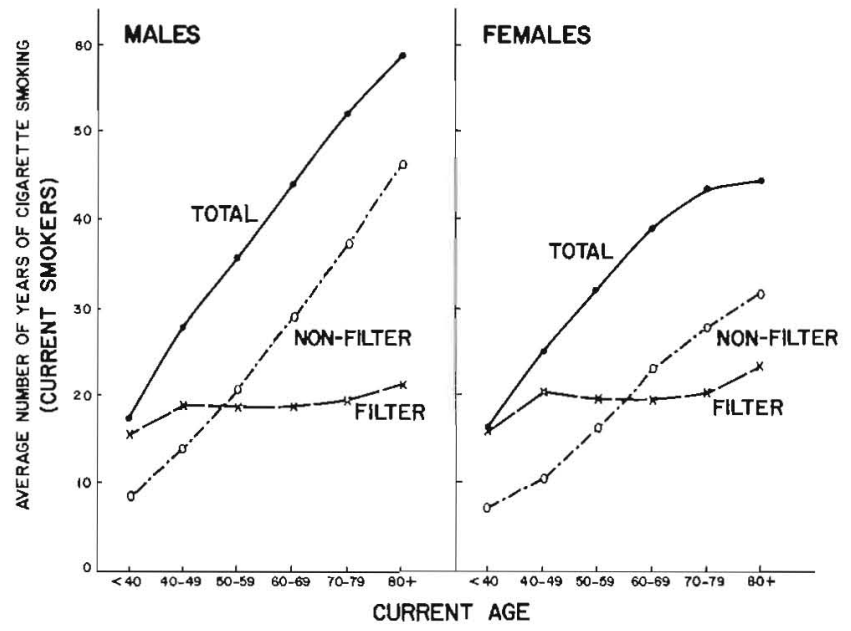

TEXT-FIGURE 4.-Average No. of yr current smokers have smoked cigarettes of all types ("TOTAL"), filter cigarettes, and nonfilter cigarettes, by age (yr) and sex. 


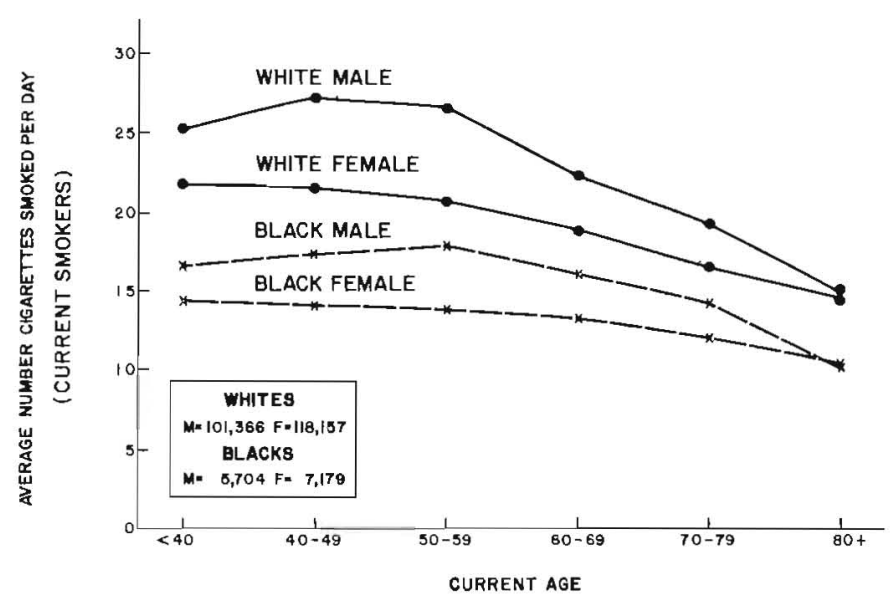

Text-Figure 5.-Average No. of cigarettes smoked/day by current smokers, by race, sex (M, males; $F$, females), and age (yr).

Text-figure 5 gives the average quantity currently consumed by smokers, by race and sex. In this population, whites smoked more cigarettes per day than did blacks; in both racial groups, men smoked more than women. There were obviously numerous economic and cultural forces at work that influenced cigarette consumption and that could be assumed to underlie differences in incidence, mortality, and survival rates from tobacco-related diseases.

We also made an interesting observation of the quantity of cigarettes smoked per day by current and former smokers, as shown in text-figure 6 . Here it appears that older men who gave up smoking were heavier smokers at the time they quit than men of the same age who continued to smoke. This finding suggested that ill health among heavy smokers may have influenced their decision to quit. However, female ex-smokers consumed significantly fewer cigarettes per day than current smokers of the same age, so that ill health may not have been so important for them in deciding to quit.
TABLE 4.-Tar content of currently smoked cigarettes

\begin{tabular}{|c|c|c|}
\hline \multirow{2}{*}{ Tar content, mg } & \multicolumn{2}{|c|}{ Percent } \\
\hline & Males $(n=89,088)$ & Females $(n=122,345)$ \\
\hline$<6.0$ & 7.8 & 13.9 \\
\hline $6.0-11.9$ & 27.0 & 37.7 \\
\hline $12.0-15.7$ & 22.3 & 28.2 \\
\hline $15.8-16.1$ & 14.5 & 2.0 \\
\hline $16.2-20.1$ & 19.6 & 14.6 \\
\hline$\geq 20.2$ & 8.8 & 3.6 \\
\hline Total & 100.0 & 100.0 \\
\hline
\end{tabular}

\section{Tar Yield of Current Cigarettes}

"Tar," measured as total particulate matter less moisture and nicotine, is a widely accepted and readily available index of biologic activity and carcinogenic potential of cigarette smoke. Stellman (14) has reviewed the evidence that strongly indicates tar yield to be directly related to higher lung cancer death rates. Cigarettes smoked today contain on the average less than one-third the tar of cigarettes available when the majority of study subjects began smoking; also, nicotine levels have fallen. No members of our cohort smoked what we now consider low-tar cigarettes throughout their lifetimes. The average tar content of U.S. cigarettes continues to decline even today, so that recording individuals' lifetime tar consumptions is a complex task.

Cigarettes were classified according to brand name, size, whether menthol, and whether filter or nonfilter. They were then assigned the tar levels as given in the tables on tar and nicotine contents published by the FTC (15). Table 4 shows the distribution of FTC tar yield in cigarettes listed as the current brand by subjects who said they were still smoking at the time of enrollment. Women chose much lower-tar cigarettes than did men; only $3.6 \%$ of female current smokers listed cigarettes having yields of $20.2 \mathrm{mg}$ or higher (most of which were nonfilters), compared to $8.8 \%$ of male current smokers. At the low-tar end of the scale, $51.6 \%$ of women
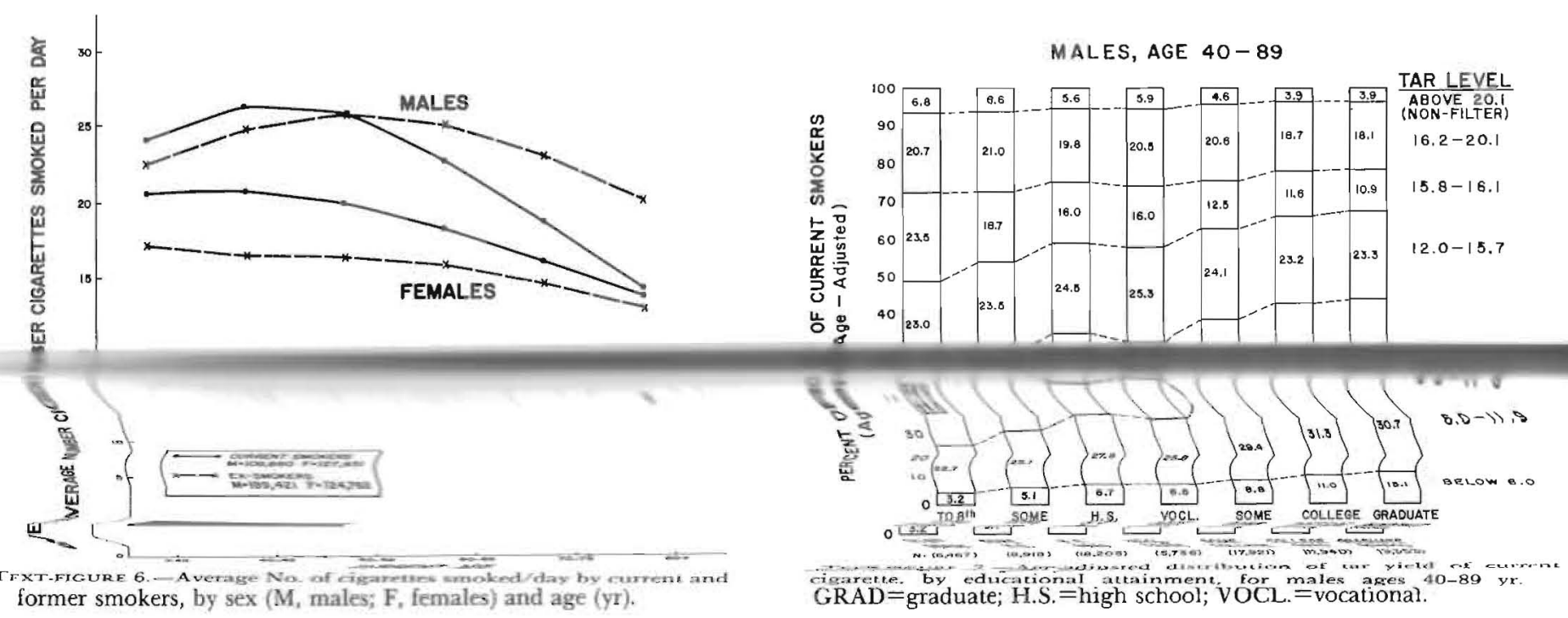

JNCI, VOL. 76, NO. 6, JUNE 1986 


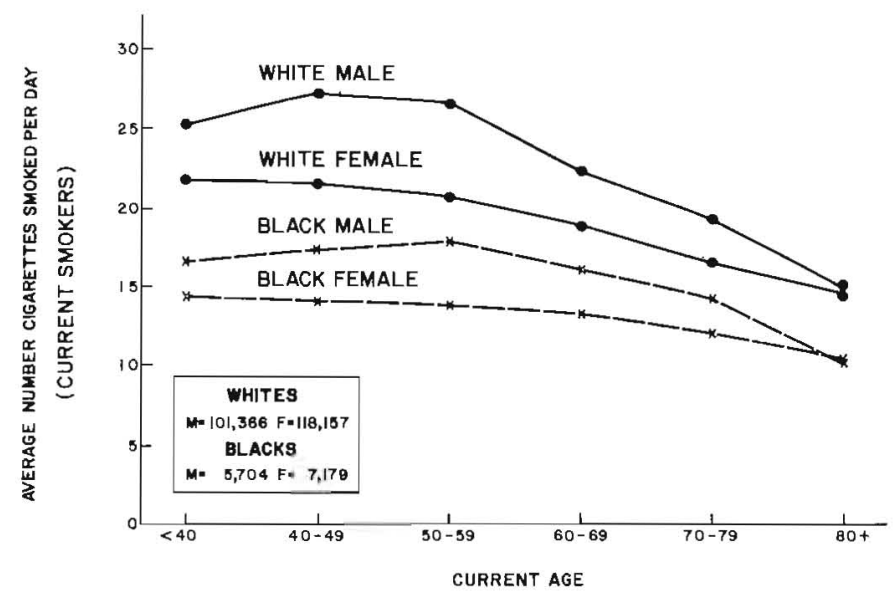

TEXT-Figure 5.-Average No. of cigarettes smoked/day by current smokers, by race, sex (M, males; F, females), and age (yr).

Text-figure 5 gives the average quantity currently consumed by smokers, by race and sex. In this population, whites smoked more cigarettes per day than did blacks; in both racial groups, men smoked more than women. There were obviously numerous economic and cultural forces at work that influenced cigarette consumption and that could be assumed to underlie differences in incidence, mortality, and survival rates from tobacco-related diseases.

We also made an interesting observation of the quantity of cigarettes smoked per day by current and former smokers, as shown in text-figure 6. Here it appears that older men who gave up smoking were heavier smokers at the time they quit than men of the same age who continued to smoke. This finding suggested that ill health among heavy smokers may have influenced their decision to quit. However, female ex-smokers consumed significantly fewer cigarettes per day than current smokers of the same age, so that ill health may not have been so important for them in deciding to quit.

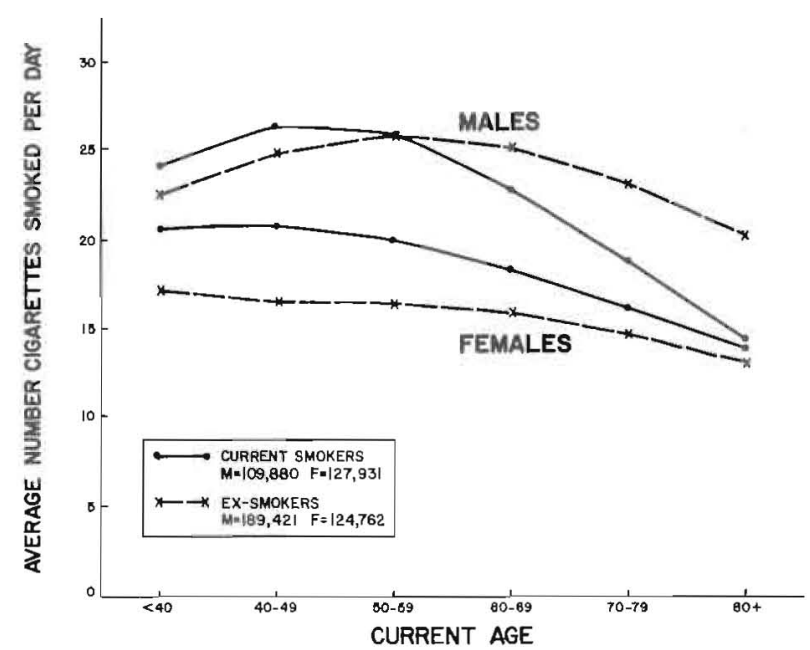

TEXT-FIGURE 6.-Average No. of cigarettes smoked/day by current and former smokers, by sex (M, males; F, females) and age (yr).
TABLE 4.-Tar content of currently smoked cigarettes

\begin{tabular}{ccc}
\hline & \multicolumn{2}{c}{ Percent } \\
\cline { 2 - 3 } Tar content, mg & Males $(n=89,088)$ & Females $(n=122,345)$ \\
\cline { 2 - 3 }$<6.0$ & 7.8 & 13.9 \\
$6.0-11.9$ & 27.0 & 37.7 \\
$12.0-15.7$ & 22.3 & 28.2 \\
$15.8-16.1$ & 14.5 & 2.0 \\
$16.2-20.1$ & 19.6 & 14.6 \\
$\geq 20.2$ & 8.8 & 3.6 \\
Total & 100.0 & 100.0 \\
\hline
\end{tabular}

\section{Tar Yield of Current Cigarettes}

"Tar," measured as total particulate matter less moisture and nicotine, is a widely accepted and readily available index of biologic activity and carcinogenic potential of cigarette smoke. Stellman (14) has reviewed the evidence that strongly indicates tar yield to be directly related to higher lung cancer death rates. Cigarettes smoked today contain on the average less than one-third the tar of cigarettes available when the majority of study subjects began smoking; also, nicotine levels have fallen. No members of our cohort smoked what we now consider low-tar cigarettes throughout their lifetimes. The average tar content of U.S. cigarettes continues to decline even today, so that recording individuals' lifetime tar consumptions is a complex task.

Cigarettes were classified according to brand name, size, whether menthol, and whether filter or nonfilter. They were then assigned the tar levels as given in the tables on tar and nicotine contents published by the FTC (15). Table 4 shows the distribution of FTC tar yield in cigarettes listed as the current brand by subjects who said they were still smoking at the time of enrollment. Women chose much lower-tar cigarettes than did men; only $3.6 \%$ of female current smokers listed cigarettes having yields of $20.2 \mathrm{mg}$ or higher (most of which were nonfilters), compared to $8.8 \%$ of male current smokers. At the low-tar end of the scale, $51.6 \%$ of women

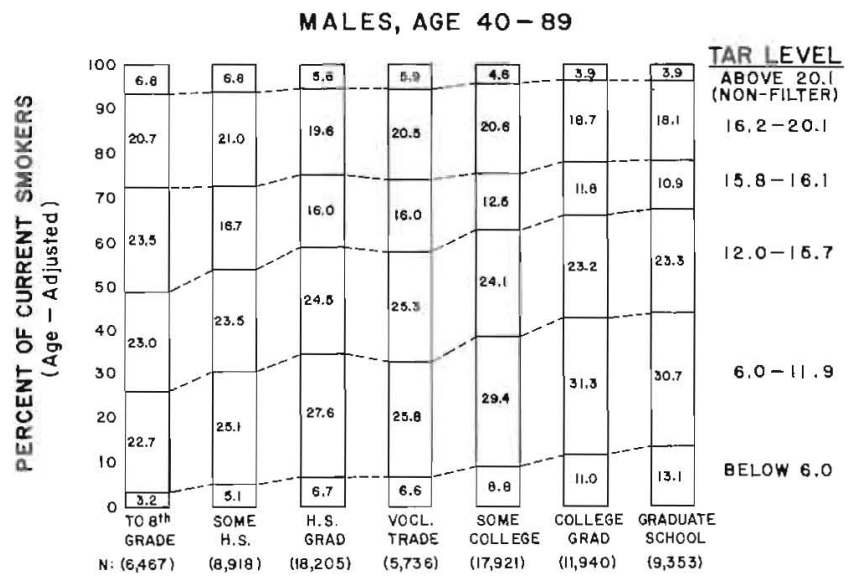

TEXT-FIGURE 7.-Age-adjusted distribution of tar yield of current cigarette, by educational attainment, for males ages 40-89 yr. $\mathrm{GRAD}=$ graduate H.S. $=$ high school VOCL $=$ vocational. 
TABLE 5.-Percentage of current male smokers according to quantity smoked, by tar level, adjusted for age

\begin{tabular}{|c|c|c|c|c|c|c|}
\hline \multirow{2}{*}{ Cigarettes/day } & \multicolumn{5}{|c|}{ Percentage of current male smokers with tar level, mg } & \multirow{2}{*}{ Nonfilter } \\
\hline & $<6$ & $6-11.9$ & $12-15.7$ & $15.8-16.1$ & $16.2-20.1$ & \\
\hline $1-9$ & 8.7 & 10.0 & 10.6 & 11.0 & 9.9 & 8.1 \\
\hline 20 & 24.3 & 28.7 & 30.3 & 32.4 & 31.3 & 34.4 \\
\hline $21-39$ & 24.3 & 23.3 & 22.4 & 20.6 & 22.7 & 21.9 \\
\hline 40 & 19.4 & 17.0 & 15.4 & 14.9 & 15.4 & 14.8 \\
\hline$\geq 41$ & 9.4 & 5.8 & 5.5 & 4.8 & 5.1 & 5.0 \\
\hline
\end{tabular}

${ }^{a}$ Cols sum to 100.0 before rounding.

smoked cigarettes with tar yields below $12.0 \mathrm{mg}$, compared to $34.8 \%$ of men.

Choice of tar levels depended both on age and education. Education was a particularly important determinant of smoking habit in men, although not so much in women. Text-figure 7 shows the age-adjusted distribution of tar content for current male smokers, according to level of educational attainment. There was a clear inverse gradient of tar yield with education; that is, men with higher levels of education weie more likely to smoke lower-tar cigarettes. Men with an education beyond college were more than four times as likely to smoke cigarettes below $6 \mathrm{mg}$ than were men with only an eighth grade education.

While it is generally believed that low-tar cigarettes have less carcinogenic potential than high-tar cigarettes, it has been suggested by some that the theoretical benefits of switching from high- to low-yield cigarettes may be lost for several reasons: Low-tar cigarettes contain untested flavoring agents that may be carcinogenic; smokers used to higher levels of nicotine (which is correlated with tar delivery) may smoke more cigarettes to maintain their pharmacologic dependency, simultaneously increasing their tar intake; and smokers may inhale more deeply for similar reasons. We have examined these last two possibilities, with results for males shown in tables 5 and 6 . Results for females were similar. The relationship between tar and quantity smoked was not overwhelming, but it was there nevertheless, particularly in smokers of more than two packs/ day. Among male current smokers of cigarettes yielding less than $6 \mathrm{mg}$ tar, $28.8 \%$ smoked at least two packs daily, compared to $19.8 \%$ of nonfilter smokers $(\geq 20.2$ $\mathrm{mg})$. However, table 6 shows that smokers of low-tar cigarettes tended to inhale less deeply, not more, if selfreports of inhalation are to be believed. The relationship between tar yield, inhalation, and quantity is complex and will be explored in detail in a future report.

\section{DISCUSSION}

Our data represent the final base-line population in a longitudinal study expected to last at least 6 years. While our population does not constitute a random sample of the United States, all regions of the country are represented in large numbers and the results are highly consistent with known smoking trends. A major biasing factor in this population is its high-educational level compared with the educational level of the general population, which means that we cannot directly generalize distributions of smoking variables. Nevertheless, the usefulness of the smoking data is demonstrated in tables 7 and 8, which show for males and females, respectively, the distribution of smoking habits with and without adjustment to the educational distribution of the United States by 10-year age groups. As expected, we would have predicted a higher percentage of male smokers in the public at large and a lower percentage of ex-smokers. Furthermore, we would have predicted more female nonsmokers.

The most striking feature of these two tables, however, is the very small change in any of the distributions introduced by adjustment for education, most below $4 \%$, indicating that the biases in our smoking distributions may in fact be much smaller than originally feared. Besides education, there are, of course, many other socioeconomic and demographic factors distinguishing this cohort from the general population. Furthermore, the

TABLE 6.-Percentage of current male smokers according to degree of inhalation, by tar level, adjusted for age

\begin{tabular}{|c|c|c|c|c|c|c|}
\hline \multirow{2}{*}{ Inhalation } & \multicolumn{5}{|c|}{ Percentage of current male smokers with tar level, mg } & \multirow{2}{*}{ Nonfilter } \\
\hline & $<6$ & $6-11.9$ & $12-15.7$ & $15.8-16.1$ & $16.2-20.1$ & \\
\hline No inhalation & 5.8 & 5.8 & 6.8 & 6.7 & 6.7 & 7.1 \\
\hline Moderate & 57.2 & 55.5 & 53.4 & 52.8 & 50.9 & 49.6 \\
\hline Deep & 23.9 & 24.6 & 25.4 & 25.9 & 29.1 & 30.6 \\
\hline Total & 100.0 & $100.0^{a}$ & 100.0 & 100.0 & 100.0 & $100.0^{a}$ \\
\hline
\end{tabular}

${ }^{a}$ Cols sum to 100.0 before rounding. 
TABLE 7.-Smoking habits of men, adjusted for education ${ }^{a}$

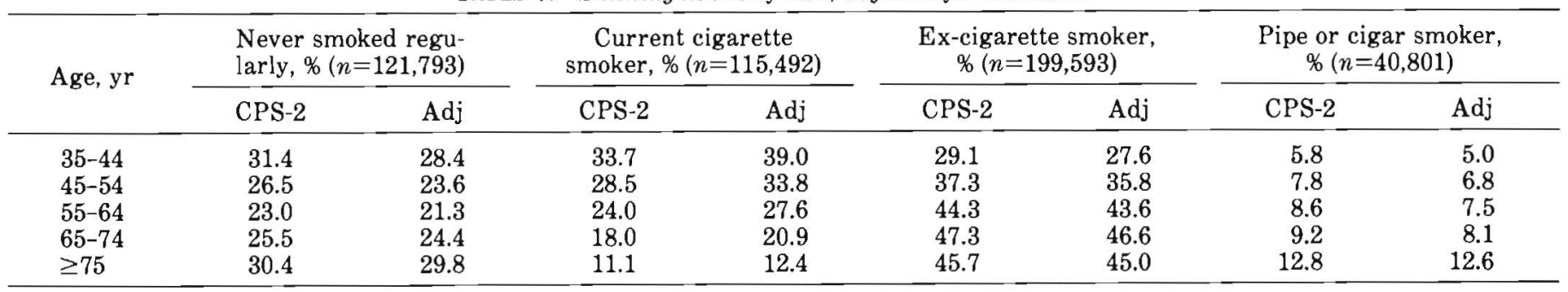

${ }^{a} \mathrm{Adj}=$ adjusted to U.S. distribution of educational attainment within age group.

lowest educational stratum of this cohort may not be comparable to the corresponding stratum of the general population. Nevertheless, while smoking is highly associated with the educational level attained, adjustment for education does not change the age-specific smoking distributions very much.

This study reflects significant changes in smoking habits that have occurred in the American population over the same era. In the two ACS studies, the percentage of current smokers among men in 1982 was half of what it was in 1959 (24.4\% in 1982 vs. $48.4 \%$ in 1959), while in women it fell from 27.2 to $21.5 \%$ during the same period. By way of comparison, the proportion of white men in the general population 45 years of age and over who were current smokers fell from $44.4 \%$ in 1965 to $30.1 \%$ in 1983 , while for women the drop was from 25.1 to $23.6 \%$ during the same time period (16).

The present study also shows that more than two times as many men (4l.4 vs. $17.3 \%)$ and four times as many women (22.1 vs. $5.6 \%$ ) quit smoking in CPS-2 compared to the predecessor CPS-1 study in 1959. Comparable population figures for white men 45 years old and over are $44.1 \%$ former smokers in 1983, up from $26.1 \%$ in 1965 ; for women, they are $19.2 \%$ in 1983 , up from $7.4 \%$ in $1965(16)$.

A second major change is the percentage of smokers who have switched to low-tar cigarettes. Many new lowtar brands ("ultras" and "lights") appeared in the late 1970's and early 1980's, which have attracted many smokers of brands higher in tar. In 1984, Wynder et al. reported on the smoking habits of hospital controls (and some community controls) interviewed between 1977 and $1982(17)$. They found that only $9 \%$ of men and $19 \%$

\begin{tabular}{|c|c|c|c|c|c|c|}
\hline \multirow[t]{2}{*}{ Age, yr } & \multicolumn{2}{|c|}{$\begin{array}{l}\text { Never smoked } \\
\text { regularly, \% } \\
(n=342,949) \\
\end{array}$} & \multicolumn{2}{|c|}{$\begin{array}{l}\text { Current ciga- } \\
\text { rette smoker, \% } \\
(n=129,629)\end{array}$} & \multicolumn{2}{|c|}{$\begin{array}{c}\text { Ex-cigarette } \\
\text { smoker, \% } \\
(n=135,214)\end{array}$} \\
\hline & CPS-2 & Adj & CPS-2 & Adj & CPS-2 & Adj \\
\hline $35-44$ & 49.9 & 49.8 & 26.6 & 30.1 & 23.5 & 20.2 \\
\hline $45-54$ & 51.8 & 53.3 & 25.0 & 27.0 & 23.2 & 19.6 \\
\hline $55-64$ & 55.9 & 59.0 & 21.4 & 22.0 & 22.7 & 19.0 \\
\hline $65-74$ & 62.6 & 66.8 & 15.8 & 15.4 & 21.6 & 17.8 \\
\hline$\geq 75$ & 79.5 & 82.2 & 7.5 & 7.1 & 13.0 & 10.7 \\
\hline
\end{tabular}

${ }^{a}$ Adj = adjusted to U.S. distribution of educational attainment within age group. of women smoked cigarettes with less than $10 \mathrm{mg}$ tar. In the CPS-2 population, which was surveyed entirely in 1982, $24.3 \%$ of male smokers and $34.5 \%$ of female smokers smoked cigarettes with less than $10 \mathrm{mg}$ tar.

Several previous studies have shown that reduced tar and nicotine have been associated with lower lung cancer mortality (14), while the results with respect to death rates from coronary heart disease and chronic obstructive pulmonary disease are not so clear (18). Those studies were based upon cigarettes categorized as "low" tar at the time but which would be classified as medium-tar brands in the 1980's. No investigations have studied the effects on mortality of brands with tar yields of less than about $15 \mathrm{mg}$. Benowitz and others (8) have shown that serum nicotine (or cotinine) levels for smokers of low-tar brands are about the same as for smokers of high-tar brands; they concluded that smokers of low-tar cigarettes must therefore compensate by inhaling more deeply. Schachter (7) demonstrated an increase over a period of weeks in the number of cigarettes smoked per day when smokers switched from a high- to a low-yield cigarette. Data from the CPS-1, however, showed that, over a long period of time, most smokers who switch to low tar (i.e., low tar in the 1960 's) tend to smoke the same number of cigarettes as the number before they switched (19).

This study suggests that smokers who switch to very low-tar cigarettes ( $<6 \mathrm{mg}$.) increase their daily consumption of cigarettes, but not to a level where they fully compensate for lower intake of nicotine. Smokers of these very low-tar cigarettes do not generally compensate by inhaling more deeply, if we go by self-reported inhalation patterns. We believe, based on this and previous studies (20), that, if smokers do compensate over a short period of time, in the long run they revert mostly to their usual method of smoking.

\section{REFERENCES}

(1) Public Health Service. Smoking and health: A report of the Surgeon General. Washington, DC: U.S. Govt Print Off, 1979 [DHEW publication No. (PBS)79-50066].

(2) Gallup Organization. 1983 survey of public awareness and use of cancer detection tests. Summary of findings. Princeton, NJ: The Gallup Organization, February 1984.

(3) American Cancer Society. Cancer facts and figures. New York: American Cancer Society, 1986.

(4) Tobacco Institute. U.S. tar/nicotine levels dropping. Tobacco Obser 1981; 6:1. 
(5) Hammond EC, Garfinkel L, Seidman H, el al. Tar and nicotine content of cigarette smoke in relation to death rates. Environ Res 1976; 12:263-274.

(6) WYNDER EL, STellman SD. Impact of long-term filter cigarette usage on lung and larynx cancer risk: A case-control study. JNCI $1979 ; 62: 471-477$.

(7) SCHACHTER S. Pharmacological and psychological determinants of smoking. Ann Intern Med 1978; 88:104-114.

(8) Benowitz NL, Hall SM, Herning RI, et al. Smokers of lowyield cigarettes do not consume less nicotine. $N$ Engl J Med 1983; 309:139-142.

(9) Robinson JC, Young JC, RicherT WS. A comprehensive study of the amount of smoke absorbed from low yield " "less hazardous") cigarettes. Part I: Noninvasive measures. Br J Addict 1982; 77:383-397.

(10) Hammond EC. Smoking in relation to the death rates of one million men and women. Natl Cancer Inst Monogr 1966; 19:127-204.

(11) U.S. Bureau of the Census. Current population reports, series P-20, No. 390. In: Educational attainment in the United States: March 1981 and 1980. Washington, DC: U.S. Govt Print Off, 1984.

(12) GREEN DE. Teenage smoking. Immediate and long-term patterns. National Institute of Education, U.S. Department of Health, Education, and Welfare. Washington, DC: U.S. Govt Print Off, Nov 1979.

(13) Smoking and health. Report of the advisory committee to the Surgeon General of the Public Health Service. Washington, DC: U.S. Govt Print Off, 1964 (PHS publication No. 1103).
(14) Stellman SD. Cigarette yield and cancer risk: Evidence from case-control and prospective studies. In: Zaridze, D, Peto R, eds. Tobacco: A major international health hazard. International Agency for Research on Cancer scientific publication No. 74. Lyon: IARC, 1986.

(15) Federal Trade Commission. Report of "tar," nicotine, and carbon monoxide of the smoke of 200 varieties of cigarettes. Washington, DC: FTC, December 1981.

(16) U.S. Department of Health and Human Services. Health: United States 1985. Washington, DC: National Center for Health Services Research, National Center for Health Statistics, Office of Health Research, Statistics, and Technology, Public Health Service. In press.

(17) Wynder EL, Goodman MT, Hoffmann D. Demographic aspects of the low-yield cigarette: Considerations in the evaluation of health risk. JNCI 1984; 72:817-822.

(18) Stellman SD. Influence of cigarette yield on risk of coronary heart disease and chronic obstructive pulmonary disease. In: Zaridze D, Peto R, eds. Tobacco: A major international health hazard. International Agency for Research on Cancer scientific publication No. 74. Lyon: IARC, 1986.

(19) Garfinkel L. Changes in cigarette consumption of smokers in relation to changes in tar/nicotine content of cigarettes smoked. Am J Public Health 1979; 69:1274-1276.

(20) … Changes in number of cigarettes smoked compared to changes in tar and nicotine content over a 13-year period. In: Gori GB, Bock FG, eds. Banbury report No. 3. A safe cigarette? Cold Spring Harbor, New York: Cold Spring Harbor Laboratory, 1980:19-24. 